\title{
Segmental lichen aureus: an uncommon presentation*
}

\author{
Pedro de Freitas Silva Torraca ${ }^{1}$ \\ Nayara de Castro Wiziack ${ }^{2}$ \\ Greicy Mara França ${ }^{1}$
}

\author{
Nathalia Dias Negrão Murback ${ }^{2}$ \\ Tânia Christina Marchesi de Freitas ${ }^{3}$
}

DOI: http://dx.doi.org/10.1590/abd1806-4841.20174781

\begin{abstract}
Pigmented purpuric dermatoses are chronic vascular inflammatory conditions characterized by the presence of pigmented macules. Among its different presentations, lichen aureus is distinguished by the lichenoid conformation of its plaques and the predilection for lower limb involvement. Its segmented form is rare and difficult to control, especially in cases of symptomatic lesions. We report a rare case of segmental lichen aureus with six years of evolution associated with light itching. We also discuss the main therapeutic approaches to control the disease.
\end{abstract}

Keywords: Lichenoid eruptions; Lichens; Purpura

\section{INTRODUCTION}

Lichen aureus is an inflammatory dermatosis considered to be a form of chronic pigmented purpuric dermatoses. ${ }^{1,2}$ Of unknown etiology, it is rare among vascular purpuric dermatoses and presents itself as a reddish, brownish, violaceous, or ferruginous well-delimited lichenoid lesion. It is localized and usually solitary, with mild or absent pruritus. It appears preferentially on lower limbs and more frequently in children and young adult males. ${ }^{13,4}$

The onset of lichen aureus is abrupt, but its course is slow, ranging from 1-7 years between the onset of the isolated initial lesions and the and rare segmental conformation. ${ }^{5}$ At this stage, lichen aureus treatment is a challenge, mainly due to the absence of the spontaneous remission and low clinical response to treatment options in cases of extensive lesions. ${ }^{2,3}$ We describe an interesting case of this rare condition in a patient in an age group outside the typical range, with multiple segmental lesions and an evolution period of six years.

\section{CASE REPORT}

A 45-year-old female patient came to our clinic with complaints of a six-year history of pink-red lesions on the right lower limb. The lesions increased progressively over time. She also reported mild pruritus (Figure 1). On dermatological examination, we observed erythematous purplish or brownish lichenoid nummular plaques of varying sizes, ranging from $1.5-8 \mathrm{~cm}$ in diameter, in the anteroposterior regions of the right leg (the lesions were more prominent in the upper half of the leg) and in the anteromedial region of the right thigh (Figure 2).
The patient reported use of topical antibiotics with no improvement of the condition. She denied comorbidities, previous trauma, and use of any other medications. Complementary examination results were normal. Anatomopathological examination revealed rectified epidermis with orthokeratosis, superficial dermis with mild perivascular inflammatory lymphohistiocytic cell infiltrate, and foci of focal exocytosis of rare lymphocytes (Figures 3 and 4). Prussian blue stain revealed deposits of hemosiderin in the dermis (Figure 5). As an initial treatment, we opted for high-potency topical corticosteroids twice a day, and 8-MOP combined with sun exposure three times a week until the return visit.

\section{DISCUSSION}

Initially described as lichen purpuricus by Martin et al. in 1958 and classified as a a form of pigmented purpuric dermatoses, the lesion was termed lichen aureus only in 1960 by Calnan. ${ }^{2,4}$ Based on its clinical morphology, lichen aureus is classified as a lichenoid eruption of confluent violaceous papules or delimited pigmented plaques, erythematous-ferruginous or purpuric in color of varying sizes. The lesions are asymptomatic in most cases. ${ }^{3,4,6}$

Although lichen aureus lesions are usually unilateral and located in the lower extremities, our patient presented multiple lesions in a zosteriform disposition with an unusual segmental aspect. ${ }^{6,7}$ These features had already been described in the literature, but in cases of segmental lichen aureus., ${ }^{2,3}$ Most of the time, lichen aureus is asymptomatic, with a slow evolution in periods of exacerbation and remission. It is more common in the second decade of life. ${ }^{2,7}$ Even

Received on 01.06.2015.

Approved by the Advisory Board and accepted for publication on 02.11.2015

* Work performed at Hospital Universitário Maria Aparecida Pedrossian da Universidade Federal de Mato Grosso do Sul (HUMAP-UFMS) - Campo Grande (MS), Brazil

Financial support: none.

Conflict of interest: none.

Department of Clinical Medicine at the Faculdade de Medicina da Universidade Federal de Mato Grosso do Sul (FAMED-UFMS) - Campo Grande (MS), Brazil Dr. Günter Hans Dermatology Service at Hospital Universitário da Universidade Federal de Mato Grosso do Sul NHU/UFMS - Campo Grande (MS), Brazil Department of Medicine at Universidade Estadual de Mato Grosso do Sul (UEMS) - Campo Grande (MS), Brazil 


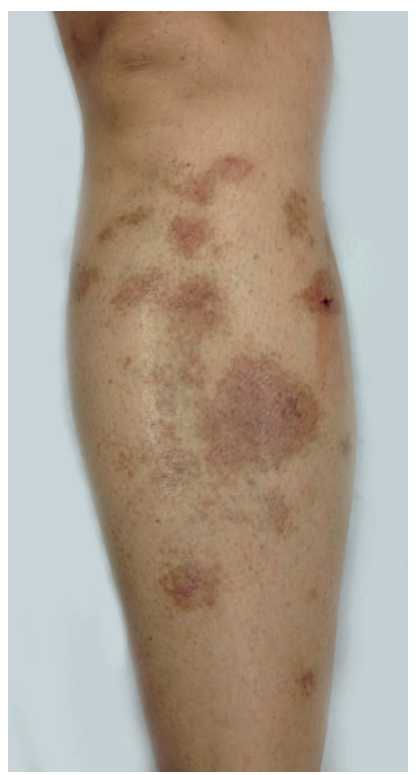

Figure 1:

Erythematous-brownish, purpuric and lichenified plaques on the upper and anteromedial right thigh

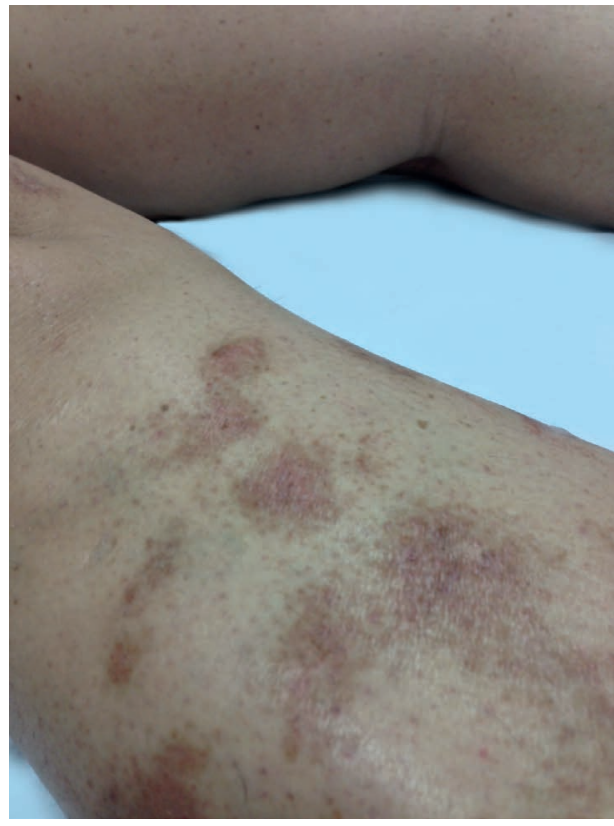

Figure 2:

Detail of the nummular appearance and varied sizes of the plaques, ranging from $1.5 \mathrm{~cm}-8 \mathrm{~cm}$ in diameter

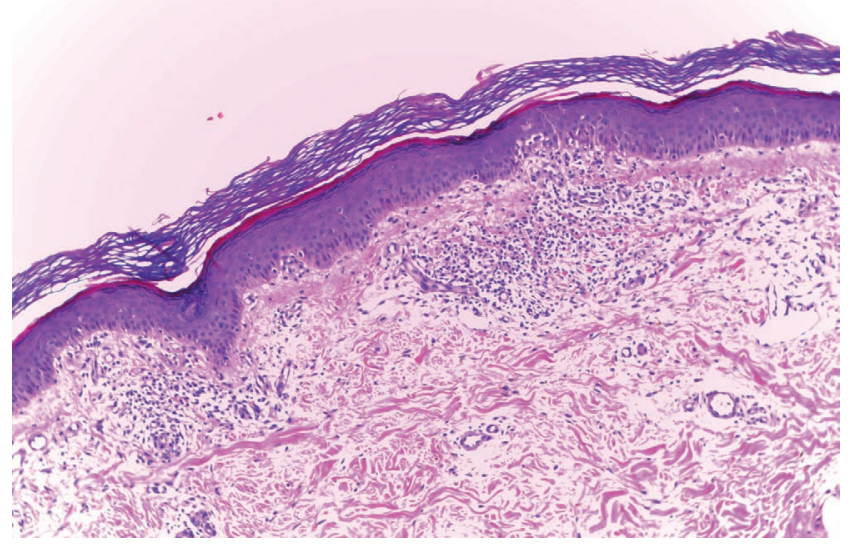

FIGURE 3: Rectification of the epidermis, orthokeratosis, and non-specific perivascular lymphohistiocytic cell infiltrate into dermis (Hematoxylin \& eosin, $\mathrm{X} 10)$

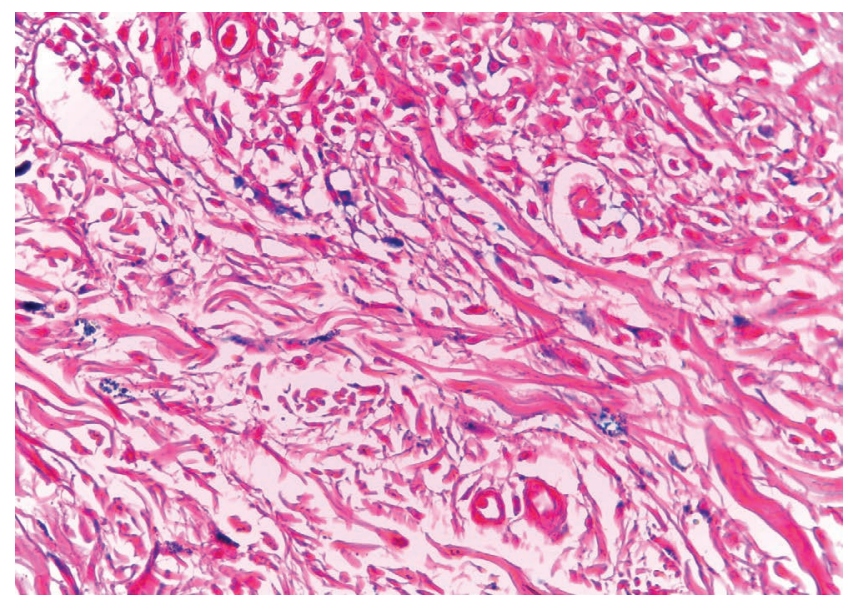

Figure 4: Mild perivascular lymphohistiocytic cell infiltration with exocytosis foci of rare lymphocytes in the dermis (Hematoxylin \& eosin, $\mathrm{X} 100)$

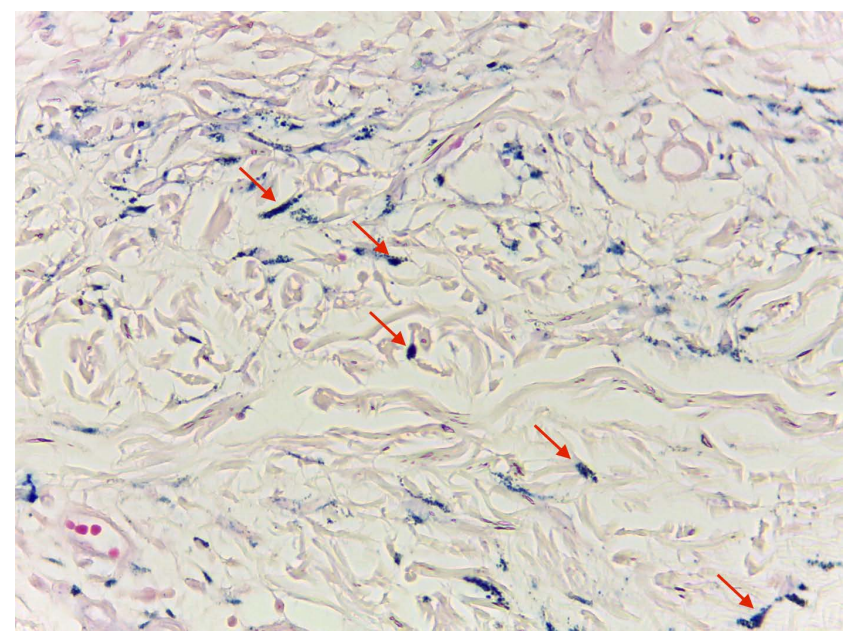

Figure 5: Deposits of hemosiderin in the dermis (arrows) Prussian blue, $\mathrm{X} 100)$

the large segmental lesion hardly ever features associated symptoms such as severe pain or pruritus. However, symptoms have already been reported in extensive purpuric lesions. ${ }^{8}$

The lichenoid reaction in the pigmentary eruption is the main characteristic that differentiates lichen aureus from other pigmented purpuric dermatoses. In its segmental presentation, this lichenoid reaction is more pronounced and can be described even in the absence of pruritus. ${ }^{3}$ Extensive lesions - in which the morphology and limits more commonly follow the venous drainage network than the dermatomes or the lines of Blaschko - have already been described in the literature as distinct presentations. ${ }^{2,3}$

Histologically, lymphocytic infiltrates seen in the upper dermis - characteristic of pigmented purpuric dermatoses along with erythrocyte extravasation and pigmentary effusion - are more prominent in the segmental presentation of lichen aureus. ${ }^{3}$ Although some reports suggest a possible association of segmental lichen aureus with purpuric fungal mycosis based on some histological similarities, there is currently no evidence of this correlation. ${ }^{2}$ Even with the 6-year duration, the present case showed no clinical 
signs of evolution to mycosis fungoides.

Currently, the treatment of lichen aureus is a challenge. Therapy with topical corticosteroids may help in the control of pigmented purpuric dermatoses, especially in cases where pruritus is reported or with more evident erythema. However, this approach is controversial in the literature. ${ }^{7}$ For lesions resistant to initial treatment with corticosteroids, topical calcineurin inhibitors may be employed. ${ }^{78}$ In lichen aureus, narrow-band PUVA and UVB treatments have been described as therapeutic options. ${ }^{3,7}$ To date, the effectiveness of using sunlight as an alternative to these approaches for segmental lichen aureus has not yet been described in the literature.

Therapies with ascorbic acid 500mg $2 x$ /daily associated with rutoside $50 \mathrm{mg} 2 \mathrm{x}$ / daily are considered adjuvant options in the control of pigmented purpuric dermatoses. A report of the use of rutoside in association with ascorbic acid in 3 patients with lichen aureus showed complete clearing of the lesions in four weeks. ${ }^{9}$ For localized lesions, there are reports of an incisional biopsy approach associated with pulsed light with duration of $12 \mathrm{~ms}$ and fluency of

\section{REFERENCES}

1. Aung PP, Burns SJ, Bhawan J. Lichen Aureus: an unusual histopathological presentation: A case report and a review of literature. Am J Dermatopathol. 2014;36:e1-4.

2. Moche J, Glassman S, Modi D, Grayson W. Segmental lichen aureus: a report of two cases treated with methylprednisolone aceponate. Australas J Dermatol. 2011;52:e15-8

3. Zhao YK, Luo DQ, Sarkar R, Xie WL. Segmental lichen aureus in a young woman with spontaneous improvement. J Dtsch Dermatol Ges. 2014;12:260-2.

4. Tortelly VD, Silva RS, Mota AN, Piñeiro-Maceira J. Agminate lichen aureus. An Bras Dermatol. 2013;88:143-5.

5. Lee HW, Lee DK, Chang SE, Lee MW, Choi JH, Moon KC. Segmental lichen aureus: combination therapy with pentoxifylline and prostacyclin. J Eur Acad Dermatol Venereol. 2006;20:1378-80.

6. Portela PS, Melo DF, Ormiga P, Oliveira FJ, Freitas NC, Bastos Júnior CS. Dermoscopy of lichen aureus. An Bras Dermatol. 2013;88:253-5.

7. Murota $\mathrm{H}$, Katayama I. Lichen aureus responding to topical tacrolimus treatment. J Dermatol. 2011;38:823-5.

8. Cunha Filho R, Schwartz J, Zanol J. Líquen aureus "algesiogênico". An Bras Dermatol. 2006;81:163-5.

9. Reinhold U, Seiter S, Ugurel S, Tilgen W. Treatment of progressive pigmented purpura with oral bioflavonoids and ascorbic acid: an open pilot study in 3 patients. J Am Acad Dermatol. 1999;41:207-8.
18J for the treatment of the residual lesion, with almost complete resolution. ${ }^{4}$

In the case of segmental lichen aureus, initial attempts to control the lesion with the combination of pentoxifylline and prostacyclin I2 demonstrated a satisfactory response when compared to the other therapeutic approaches. ${ }^{5}$ Currently, several cases suggest methylprednisolone acetate (MPA) $0.1 \%$ topical as a treatment option. In two cases of segmental lichen aureus, MPA $0.1 \%$ topical led to the complete resolution of the extensive lesions after 4-7 months of continuous use, with no relapse in the 11 months of follow-up. ${ }^{2}$ In the present case, initial treatment consisted of betamethasone $2 x$ / day associated with three cycles of 8-MOP and sun exposure (as an alternative to UVA/UVB) 3x/week, with return after 30 days. After that period, the patient reported improvement of the lesions.

\author{
MAILING ADDRESS: \\ Pedro de Freitas Silva Torraca \\ Av. Senador Filinto Müller, 1 - Pioneiros \\ 79080-190 Campo Grande, MS - Brazil \\ E-mail:pftorraca@gmail.com
}

How to cite this article: Torraca PFS, Murback NDN, Wiziack NC, Freitas TCM, França GM. Segmental Lichen aureus: an uncommon presentation. An Bras Dermatol. 2017;92(5):704-6. 